\title{
SINERGIA
}

REVISTA DO INSTITUTO DE CIÊNCIAS ECONÔMICAS, ADMINISTRATIVAS E CONTÁBEIS (ICEAC)

\section{ATIVIDADE DE ESTÁGIO: UM ESTUDO ACERCA DA CONTRIBUIÇÃO PARA A FORMAÇÃO PROFISSIONAL, QUALIDADE DE VIDA E BEM-ESTAR DOS ESTAGIÁRIOS}

\author{
CAROLINA SOUZA VALORIA \\ FLÁVIA REGINA COSTA CZARNESKI \\ DÉBORA GOMES MACHADO"**
}

\begin{abstract}
RESUMO
As atividades de estágio são o primeiro contato dos alunos com a realizada prática de sua área de estudo, tornando-se forma de complementação dos estudos acadêmicos com a formação em centros de trabalho. Este estudo consistiu em analisar as atividades de estágio realizadas pelos alunos do ICEAC, entre os anos de 2014 e 2015, para identificar a contribuição na formação profissional, na QVT e no bem-estar dos estagiários. O trabalho se justifica a partir da busca pelo entendimento atual das relações entre estagiário e empregador e se nelas agregam conhecimento, experiência, contribuição mútua e geram aprendizado de competências próprias na atividade profissional. Neste estudo, considerase que a QVT, quando trabalhada pelas organizações, tem como foco principal o bem-estar dos trabalhadores em seu contexto de trabalho. O estudo se caracteriza como uma pesquisa quantitativa e descritiva. Compuseram a amostra alunos dos cursos de Administração, Ciências Contábeis e Ciências Econômicas de uma Universidade Pública do Sul do país, que realizaram a atividade de estágio. Para a coleta dos dados, utilizou-se um questionário embasado nos 10 indicadores de bem-estar e QVT estudados por Paz (2004), Warr (2007) e Dessen (2010). Os resultados obtidos indicam que os estagiários estão satisfeitos com a autonomia que possuem na organização, sentem-se ouvidos e consideram importantes as capacitações recebidas. Mas não estão satisfeitos com a pouca liberdade para atuar e com a falta de interesse das organizações em programa de carreira, pois são escassas as chances de efetivação.
\end{abstract}

Palavras-chave: Estágio; Atividade profissional; bem-estar; QVT

\section{ABSTRACT}

The internship activities are the students' first contact with the practice of their area of study, becoming a form of complementation of academic studies with training in work centers. This study consisted of analyzing the internship activities carried out by the ICEAC students between the years 2014 and 2015 to identify the contribution in vocational training, QWL and the welfare of trainees. The work is justified by the search for the current understanding of the relations between trainee and employer and if in them they add knowledge, experience, mutual contribution and generate learning of own competences in the professional activity. In this study, it is considered that the QVT, when worked by the organizations, has as main focus the well-being of the workers in their work context. The study is characterized as a quantitative and descriptive research. The sample comprised students of the courses of administration, accounting sciences and economic sciences of a Public University of the south of the country, that carried out the activity of internship. For the data collection, a questionnaire based on the 10 well-being and QWL indicators studied by Paz (2004), Warr (2007) and Dessen (2010) was used. The results indicate that the trainees are satisfied with the autonomy they have in the organization, they feel heard and consider important to the training received; but they are not satisfied with the lack of freedom to act and the lack of interest of the organizations in the career program, since the chances of effectiveness are scarce.

Keywords: Stage; Professional activity; welfare; QVT

Recebido em: 03-04-2018 Aceito em: 05-06-2018

\section{INTRODUÇÃO}

As atividades de estágio são o primeiro contato dos alunos com a prática realizada de sua área de estudo. Por anos, essa vertente era utilizada apenas para contratação de mão de obra barata, pela baixa remuneração e grande vontade de os estagiários crescerem e aprenderem. Roesch (1996) salienta que, muitas vezes, as organizações colocam os estagiários para exercer atividades repetitivas, sem oportunidade de aprender um trabalho ligado à profissão, ou de conhecer outras atividades, aproveitando o

\footnotetext{
"Graduada em Administração pela Universidade Federal do Rio Grande - FURG

Doutora em Engenharia de Produção pela Universidade Federal de Santa Catarina e Professora da Universidade Federal do Rio Grande

"Doutora em Ciências Contábeis e Administração pela Universidade Regional de Blumenau e Professora da Universidade Federal do Rio Grande
} 
estagiário como uma maneira de obter mão de obra barata. A autora salienta, também, que qualquer experiência de trabalho é válida, pois ensina como se relacionar com colegas, superiores, clientes e saber como funciona uma organização.

No Brasil, a Lei $n^{\circ} 11.788$, de 25 de setembro de 2008, conceitua o estágio como 0 ato educativo escolar supervisionado, desenvolvido no ambiente de trabalho, que visa à preparação para o trabalho produtivo de educandos que estejam frequentando o ensino regular em instituições de educação superior, de educação profissional, de ensino médio, da educação especial e dos anos finais do ensino fundamental, na modalidade profissional da educação de jovens e adultos. (BRASIL, 2008).

De acordo com Colombo e Ballão (2014), no Brasil, as mudanças no conceito de estágio foram acompanhadas pela legislação educacional. Os debates em torno de uma nova legislação sobre estágio, ocorrida no Congresso Nacional Brasileiro, a partir da primeira década do século XXI, demonstrou a existência de um confronto entre aqueles que defendiam o estágio com foco no interesse da escola e os que focavam o interesse das empresas.

Conforme Zabalza (2015), por meio do estágio, pretende-se estabelecer uma alternância ou complementação dos estudos acadêmicos com a formação em centros de trabalho. Em sua formação, os estudantes passam um período de sua formação em universidades e/ou centros de formação específicos e outro período em instituições, de acordo com sua área de atuação. Salvo essas condições constantes, todas as outras características do estágio podem variar de um programa para outro. A atividade de estágio é o primeiro 'trabalho' dos alunos e, segundo Codo (2006), o trabalho é o modo pelo qual se transmite significado à natureza e pode ser entendido como um dos elementos essenciais na constituição da identidade do indivíduo.

Por anos, a atividade de estágio era utilizada apenas para contratação de mão de obra barata, pela baixa remuneração e grande vontade de os estagiários crescerem e aprenderem. Além disso, as tarefas atribuídas a eles eram de pouco uso intelectual, geralmente as que ninguém gostava de fazer. Assim, têmse como problemas de pesquisa: qual a visão do aluno estagiário quanto às atividades de estágio que realizou? O estágio está sendo utilizado como meio de experiência para agregar conhecimento?

Para se estabelecer essa identidade entre trabalho e identidade do indivíduo, busca-se relacionar as temáticas 'Qualidade de Vida no Trabalho (QVT)' e 'bem-estar'. A QVT tem como foco principal o bem-estar e valorização do trabalhador, trazendo humanização, produtividade e eficiência no ambiente de trabalho. Nesse contexto, o trabalho buscará entender quais as contribuições, relevância social, oportunidade de crescimento e outros fatores relevantes nas atividades de estágio, levando em consideração os dez indicadores de Dessen (2010), apresentados na revisão da literatura.

Para Warr (2007), o ambiente exerce influência na saúde mental das pessoas, pois o bem-estar de um indivíduo dependerá de quanto o seu ambiente lhe proporciona oportunidades de experiências positivas , quanto são percebidas e aproveitadas. Estas ideias também se a plicam ao ambiente de trabalho, o qual possui características que influenciam o bem-estar dos indivíduos. Paz (2004) define bem-estar como sendo a satisfação de necessidades e a realização de desejos dos indivíduos ao desempenhar o seu papel na organização.

Assim, qualidade de vida no trabalho será entendida pela visão de Dessen (2010), cuja autora acredita que a temática deva ser compreendida como a parte que cabe à organização promover. Ademais, acarreta planejamento e realização de ações que visem ao aumento do bem-estar e contribuam para tal. Enquanto o bem-estar é uma variável subjetiva, a QVT é objetiva e descritiva, implica uma avaliação do que a organização faz de concreto para que o bem-estar ocupacional de seus membros seja garantido. Dessa maneira, sua análise pode levar em consideração a percepção dos trabalhadores com relação a tais ações, mas, diferentemente do bem-estar, os afetos não são incluídos nessa medida. (DESSEN, 2010).

É nessa perspectiva que nasce o interesse em pesquisar sobre a qualidade de vida no trabalho (QVT) e bem-estar dos estagiários dos cursos de Administração, Ciências Contábeis e Ciências Econômicas. Nesse contexto, este estudo tem objetivo levantar a percepção dos alunos dos cursos de Administração, Ciências Contábeis e Ciências Econômicas, de uma universidade pública federal, que realizaram atividade de estágio entre os anos de 2014 a 2015, quanto à contribuição da atividade de estágio na sua formação profissional, na QVT e no bem-estar.

O estudo fomenta as contribuições, relevância social, oportunidade de crescimento e outros fatores relevantes nas atividades de estágio, levando em consideração os dez indicadores de Dessen (2010). O entendimento da atividade de estágio para os estagiários, professores, empresários, empregados em geral, sociedade poderá possibilitar uma nova percepção desta modalidade de ensino-aprendizagem e evidenciar como contribuição de estudo para a área. 


\section{REVISÃO DA LITERATURA}

\subsection{Qualidade de vida no trabalho (QVT)}

Sob uma perspectiva organizacional, pessoas são recursos valiosos, mas, em geral, subutilizados em seu potencial, com reflexos nos resultados globais da empresa. Nesse sentido, o entendimento de que o empregado deve ser visto como ser humano, com necessidades econômicas e sociais e psicológicas, tem demonstrado ser, antes de tudo, uma inteligente atitude empresarial. Isso se deve pela decorrência do contexto sociopolítico da época, em que as empresas precisavam conviver com uma classe trabalhadora em evolução, que apresentava novas características, incluindo nível de informação mais elevado, maior consciência social de sua importância, desejos de participação mais elevados nas decisões que a afetavam, além de um sindicalismo mais atuante. (FERNANDES; GUTIERRES, 1988)

Os autores destacam que, em geral, as pessoas acreditam que, quando se trata de melhoria da qualidade de vida, a ideia associada é a melhoria das condições físicas, instalações, reivindicações salariais, diminuição da forma de trabalho, de benefícios e etc, o que implica custos, aumento das despesas, mudanças. A partir disso, surgem barreiras à implementação do programa de QVT, por parte do administrador. De acordo com Fernandes e Gutierres (1988), existem fatores organizacionais, ambientais e comportamentais que influenciam o nível de satisfação e produtividade. Conforme os autores, a QVT referese a esforços no sentido de melhorar ou humanizar a situação do trabalho, orientados por soluções mais adequadas em pesquisas e estudos que visem à reformulação e às condições negativas dos cargos, tornando mais produtivos em termos de empresa e mais satisfatórios para os executores.

A qualidade de vida no trabalho proporciona uma maior participação por parte dos funcionários, criando um ambiente de integração com superiores, com colegas de trabalho, com o próprio ambiente de trabalho, visando sempre à compreensão das necessidades dos funcionários. A QVT se preocupa, principalmente, com dois aspectos importantes: o bem-estar do trabalhador e a eficácia organizacional. Com a necessidade das empresas se tornarem mais competitivas no mercado, veio a busca incessante da qualidade total. Acompanhando esta qualidade total, também surgiu a QVT, que está focalizada no potencial humano e no meio que convive em todos os sentidos. Um programa adequado de QVT busca uma organização mais humanizada e proporciona condições de desenvolvimento pessoal ao indivíduo. (MORETTI, 2003).

Dessen (2010) interpreta que a QVT, apesar de apresentar diferentes definições e modelos, tem algumas semelhanças com a teoria sobre bem-estar ocupacional, isso porque os dois conceitos se preocupam com a criação de um ambiente que leve mais em consideração as necessidades dos empregados, enfatizando a importância de se sentirem bem quanto ao trabalho que executam.

\subsection{Bem-estar no trabalho}

Para Siqueira e Padovam (2008), o bem-estar no trabalho é entendido como um construto psicológico multidimensional, integrado por vínculos afetivos positivos com o trabalho (satisfação e envolvimento) e com a organização (comprometimento organizacional afetivo). Os autores destacam três conceitos com conotações positivas que auxiliam na proposta de conceito de bem-estar no trabalho: a) satisfação no trabalho derivado de experiências positivas; $b$ ) envolvimento com o trabalho, especificamente o quanto o seu desempenho possa afetar a sua autoestima e, por fim, c) comprometimento organizacional afetivo, que seria o desejo de se manter na organização com a finalidade de realizar seus objetivos.

Para Zanelli, Borges-Andrade e Bastos (2014), o conhecimento sobre as condições de trabalho se organiza em dois eixos: priorização das influências do ambiente sobre o bem-estar do indivíduo/trabalhador e o enfoque nas influências sobre a saúde. Segundo os autores, o bem-estar recebe uma conotação abrangente: além de abarcar o próprio conceito de saúde, também inclui aspectos afetivos, como satisfação/insatisfação, experimentadas pelo indivíduo em diversas áreas de sua vida (social, familiar, espiritualidade), e satisfações/insatisfações relativas ao trabalho (salário, promoção na empresa, chefia e colegas).

Já Dessen (2010) compara todos esses indicadores de bem-estar subjetivo à qualidade de vida no trabalho, que é objetiva. A autora exemplifica a existência de organizações que oferecem condições de trabalho excelentes e pode ocorrer que, em face dessas mesmas condições, alguns indivíduos sintam bemestar e outros não. O mesmo ocorre em organizações que não oferecem condições apropriadas ao seu empregado, uma vez que podem ser encontradas pessoas que não se sentem bem com isso e outras que estão adaptadas. A autora aborda que existe a preocupação dos dois conceitos criarem um ambiente que leve em consideração as necessidades dos empregados, enfatizando a importância de que eles se sintam bem diante do trabalho que executam, ou seja, ambos visam o bem-estar dos trabalhadores havendo similaridades com relação aos indicadores citados nas duas abordagens, que podem ser observados no Quadro 1. 
QUADRO 1 - Relação entre indicadores de bem-estar e dimensões da QVT

\begin{tabular}{|l|l|}
\hline INDICADORES DE BEM-ESTAR & \multicolumn{1}{|c|}{ DIMENSÕES DE QVT } \\
\hline Autonomia & $\begin{array}{l}\text { Oportunidade de utilização e desenvolvimento da capacidade } \\
\text { humana } \\
\text { Autonomia } \\
\text { Dimensão sociológica } \\
\text { Elementos comportamentais } \\
\text { Natureza do trabalho }\end{array}$ \\
\hline Suporte ambiental & $\begin{array}{l}\text { Condições de segurança e saúde do trabalho } \\
\text { Contexto físico }\end{array}$ \\
\hline Salário & $\begin{array}{l}\text { Compensação Justa e Adequada } \\
\text { Dimensão Econômica } \\
\text { Contexto Organizacional }\end{array}$ \\
\hline Oportunidades de crescimento & $\begin{array}{l}\text { Oportunidades futuras para crescimento contínuo } \\
\text { segurança } \\
\text { Contexto organizacional }\end{array}$ \\
\hline Relação com clientes & $\begin{array}{l}\text { Integração social na organização } \\
\text { Relacionamento interpessoal } \\
\text { Contexto psicossocial }\end{array}$ \\
\hline Relação com colegas de trabalho & $\begin{array}{l}\text { Relacionamento Interpessoal } \\
\text { Contexto psicossocial }\end{array}$ \\
\hline Relação com a chefia & $\begin{array}{l}\text { Integração social na organização } \\
\text { Relacionamento interpessoal } \\
\text { Contexto psicossocial }\end{array}$ \\
\hline Valorização do trabalho & $\begin{array}{l}\text { Oportunidade de utilização e desenvolvimento da capacidade } \\
\text { humana } \\
\text { Variedade de habilidades } \\
\text { Identidade com a tarefa } \\
\text { Dimensão psicológica } \\
\text { Elementos ambientais } \\
\text { Elementos comportamentais } \\
\text { Natureza do trabalho }\end{array}$ \\
\hline Identificação com a organização & $\begin{array}{l}\text { Oportunidade de utilização e desenvolvimento da capacidade } \\
\text { humana } \\
\text { Significado da tarefa }\end{array}$ \\
\hline $\begin{array}{l}\text { Relevância social do trabalho } \\
\text { Constitucionalismo }\end{array}$ \\
\hline
\end{tabular}

FONTE: Adaptado de Dessen (2010)

O conceito de bem-estar ocupacional, na visão de Dessen (2010), é quando um trabalhador afirma se sentir bem com relação a um indicador, isso significa que a organização proporcionou um ambiente propício e que ele aproveitou as oportunidades por ela oferecidas, ou seja, essa variável é mais subjetiva que a de QVT. Já a QVT, como já conceituada é objetiva e descritiva. Há uma implicação em uma avaliação do que a organização faz de concreto para que o bem-estar ocupacional de seus membros seja garantido, ou seja, sua análise pode levar em consideração a percepção dos trabalhadores com relação a tais ações, mas, diferentemente do bem-estar, os afetos não são incluídos nesta medida.

Para Paz (2004) é nos recursos financeiros que o indivíduo pode perceber justiça na relação entre o trabalho que realiza e o salário que recebe. Warr (2007) também aborda este ponto ao mencionar que os salários são capazes de atender às necessidades pessoais e familiares dos trabalhadores. $O$ autor coloca, ainda, que o bem -estar parece depender das relações estabelecidas com as outras pessoas e aponta a ajuda recebida delas como um elemento essencial. Assim, o suporte do supervisor, especialmente no que se refere à aceitação de ideias, à participação e ao bem-estar de sua equipe, se torna essencial.

Paz (2004) ressalta que o orgulho à organização relaciona-se a satisfação e a identificação do trabalhador com a empresa e se torna um importante fator de bem-estar. Warr (2007) faz referência a percepção de justiça na relação entre o trabalhador e a organização, assim como entre a organização e a sociedade. Estes aspectos são relacionados à responsabilidade social e à justiça organizacional .

Já relacionado às condições de trabalho, Warr (2007) referencia o ambiente físico, como segurança, salientando a importância das metas e da clareza do ambiente. Já Paz (2004), referencia o suporte ambiental, onde a autonomia é considerada muito importante ao propor ao individuo condições de liberdade 
para ajustar a execução de seu trabalho às suas características pessoais.

Como a literatura aponta, a possível relação entre características individuais e organizacionais afetam a QVT e o bem-estar no trabalho. A seguir, apresentam-se os procedimentos metodológicos aplicados para levantar a percepção dos alunos que realizaram atividade de estágio, quanto à contribuição da atividade de estágio na sua formação profissional, na QVT e no bem-estar.

\section{PROCEDIMENTOS METODOLÓGICOS}

Segundo Rampazzo (2005), a pesquisa é um procedimento reflexivo, sistemático, controlado e crítico, que permite descobrir novos fatos ou dados, soluções ou leis, em qualquer área do conhecimento. Dessa forma, a pesquisa é uma atividade voltada para solução de problemas por meio de processos do método científico.

Para atingir o objetivo de analisar a percepção dos alunos dos cursos de Administração, Ciências Contábeis e Ciências Econômicas, de uma Universidade Pública do Sul do país, quanto à atividade de estágio, adotou-se o estudo de caráter quantitativo e descritivo que, segundo Souza, Santos e Dias (2013), tem como objetivo primordial a descrição das características de determinada população ou fenômeno ou o estabelecimento de relações entre variáveis. Rampazzo (2005) destaca que a pesquisa descritiva observa, registra, analisa e correlaciona fatos ou fenômenos (variáveis), sem manipulá-los, ou seja, sem a interferência do pesquisador. Para Gil (2008), a pesquisa descritiva visa descrever as características de determinadas populações ou fenômenos . Uma de suas peculiaridades está na utilização de técnicas padronizadas de coleta de dados, tais como o questionário e a observação sistemática.

A população da pesquisa consiste em 158 alunos dos cursos acima mencionados, que realizaram a atividade de estágio nos anos de 2014 e 2015. A amostra foi composta pelos 67 alunos que responderam ao questionário enviado, totalizando $42,4 \%$ da população.

Para obter os resultados, foi elaborado um questionário estruturado, com 6 perguntas fechadas, para definição do perfil dos respondentes e outras 60 perguntas fechadas, para a análise das atividades de estágio, quanto à QVT e ao bem-estar, baseado no estudo de Dessen (2010) e de acordo com os indicadores apresentados na Figura 1.

Para responder as questões, utilizou-se a escala de Likert, para cada uma das afirmações, o respondente poderia escolher entre 5 alternativas, sendo: 'discordo totalmente', 'discordo em partes', 'não concordo nem discordo', 'concordo em partes' e 'concordo totalmente'. O questionário foi elaborado com base em Paz (2004); Dessen (2010) e Warr (2007) e enviado para o e-mails dos alunos através de um link do 'docs.google'.

\section{APRESENTAÇÃO E ANÁLISE DOS RESULTADOS}

A atividade de estágio foi analisada diante de 10 indicadores estudados por Paz (2004), Warr (2007) e Dessen (2010), que abordam os entendimentos sobre QVT e bem-estar, que são: autonomia; suporte ambiental; salário; oportunidades de crescimento; relação com clientes; relação com colegas de trabalho; relação com a chefia; identificação com o trabalho; valorização do trabalho e; identificação com a organização. O instrumento pode ser visualizado no Quadro 2, elaborado a partir de Paz (2004), Warr (2007) e Dessen (2010). Os dados numéricos apresentados correspondem aos dados encontrados na pesquisa e estão consolidados nos critérios que tiveram o maior número de incidências, agrupando as alternativas 'discordo totalmente' com as 'discordo em partes'; e as 'concordo totalmente' com as 'concordo em partes'.

QUADRO 2 - Base do instrumento de coleta de dados

\begin{tabular}{|c|c|c|c|c|}
\hline & \multicolumn{2}{|l|}{ QVT } & \multicolumn{2}{|l|}{ BEM-ESTAR } \\
\hline & QUESTÕES & TOTAL* & QUESTÕES & TOTAL* \\
\hline \multirow{6}{*}{ 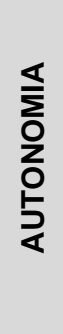 } & \multirow{2}{*}{$\begin{array}{l}\text { Liberdade para realizar o trabalho e } \\
\text { tomar algumas decisões. }\end{array}$} & Concordo & \multirow{2}{*}{ A opinião do estagiário era considerada. } & Concordo \\
\hline & & $73,2 \%$ & & $47,8 \%$ \\
\hline & \multirow{2}{*}{$\begin{array}{l}\text { A organização considerava a opinião } \\
\text { dos outros menos a do estagiário. }\end{array}$} & Discordo & \multirow{2}{*}{$\begin{array}{l}\text { O estagiário tinha liberdade para } \\
\text { executar atividades. }\end{array}$} & Discordo \\
\hline & & $77,6 \%$ & & $41,8 \%$ \\
\hline & \multirow{2}{*}{$\begin{array}{c}\text { A empresa dava autonomia para } \\
\text { apresentar solução para os } \\
\text { problemas. }\end{array}$} & Concordo & \multirow{2}{*}{$\begin{array}{c}\text { O estagiário tinha autonomia para sugerir } \\
\text { novas ideias. }\end{array}$} & Concordo \\
\hline & & $61,2 \%$ & & $76,1 \%$ \\
\hline
\end{tabular}




\begin{tabular}{|c|c|c|c|c|}
\hline & \multicolumn{2}{|l|}{ QVT } & \multicolumn{2}{|l|}{ BEM-ESTAR } \\
\hline & QUESTÕES & TOTAL* & QUESTÕES & TOTAL* \\
\hline \multirow{6}{*}{ 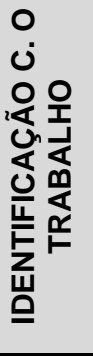 } & \multirow{2}{*}{$\begin{array}{l}\text { A organização possibilitava o } \\
\text { desenvolvimento do potencial. }\end{array}$} & Concordo & \multirow{2}{*}{$\begin{array}{l}\text { Quando trabalhava na organização, o } \\
\text { estagiário desenvolvia seu potencial. }\end{array}$} & Concordo \\
\hline & & $73,1 \%$ & & $76,2 \%$ \\
\hline & \multirow{2}{*}{$\begin{array}{c}\text { A organização variava as tarefas para } \\
\text { que pudesse usar capacidades } \\
\text { diferentes. }\end{array}$} & Discordo & \multirow{2}{*}{ O estagiário sentia interesse nas tarefas. } & Concordo \\
\hline & & $37,3 \%$ & & $61,2 \%$ \\
\hline & \multirow{2}{*}{$\begin{array}{l}\text { A organização oferecia condições } \\
\text { para aprender com a realização do } \\
\text { estágio. }\end{array}$} & Concordo & \multirow{2}{*}{$\begin{array}{l}\text { O estagiário gostava da variedade de } \\
\text { tarefas que realizava. }\end{array}$} & Concordo \\
\hline & & $79,1 \%$ & & $59,7 \%$ \\
\hline \multirow{6}{*}{ 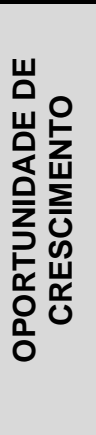 } & \multirow{2}{*}{$\begin{array}{l}\text { A empresa possuía um programa de } \\
\text { carreira e crescimento para seus } \\
\text { colaboradores. }\end{array}$} & Discordo & \multirow{2}{*}{$\begin{array}{l}\text { O estagiário percebia a oportunidade de } \\
\text { aprender por meio de capacitações } \\
\text { oferecidas pela organização. }\end{array}$} & Concordo \\
\hline & & $38,8 \%$ & & $58,2 \%$ \\
\hline & \multirow[t]{2}{*}{$\begin{array}{l}\text { A organização proporcionava chances } \\
\text { de efetivação dos estagiários. }\end{array}$} & Discordo & \multirow[t]{2}{*}{$\begin{array}{l}\text { O estagiário gostava do sistema de } \\
\text { promoção da empresa. }\end{array}$} & $\begin{array}{c}\text { Não } \\
\text { concordo } \\
\text { nem } \\
\text { discordo }\end{array}$ \\
\hline & & $50,7 \%$ & & $40,3 \%$ \\
\hline & \multirow{2}{*}{$\begin{array}{c}\text { A organização capacitava os } \\
\text { colaboradores antes de preferir trazer } \\
\text { profissionais de fora. }\end{array}$} & Concordo & \multirow{2}{*}{$\begin{array}{l}\text { O estagiário tinha conhecimento dos } \\
\text { critérios para as promoções. }\end{array}$} & Discordo \\
\hline & & $37,3 \%$ & & $31,3 \%$ \\
\hline \multirow{6}{*}{ 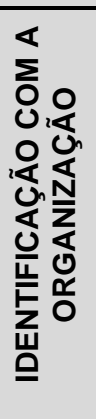 } & \multirow{2}{*}{$\begin{array}{c}\text { O mérito do sucesso da organização } \\
\text { era compartilhado com a equipe de } \\
\text { colaboradores. }\end{array}$} & Concordo & \multirow{2}{*}{$\begin{array}{l}\text { O estagiário acreditava no resultado do } \\
\text { trabalho da organização. }\end{array}$} & Concordo \\
\hline & & $61,2 \%$ & & $58,2 \%$ \\
\hline & \multirow{2}{*}{$\begin{array}{l}\text { A organização proporcionava um } \\
\text { ambiente no qual os colaboradores } \\
\text { sentiam orgulho em fazer parte da } \\
\text { mesma. }\end{array}$} & Concordo & \multirow[t]{2}{*}{$\begin{array}{l}\text { O estagiário sentia orgulho de pertencer } \\
\text { àquela organização. }\end{array}$} & $\begin{array}{l}\text { Não } \\
\text { concord } \\
\text { nem } \\
\text { discordo }\end{array}$ \\
\hline & & $58,2 \%$ & & $40,3 \%$ \\
\hline & \multirow{2}{*}{$\begin{array}{l}\text { A organização acreditava que todas } \\
\text { as tarefas eram essenciais para a } \\
\text { sociedade. }\end{array}$} & Concordo & \multirow{2}{*}{$\begin{array}{l}\text { O estagiário se identificava com aquela } \\
\text { organização. }\end{array}$} & Concordo \\
\hline & & $65,7 \%$ & & $32,8 \%$ \\
\hline \multirow{6}{*}{ 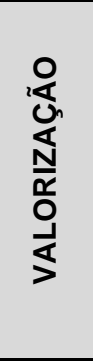 } & \multirow{2}{*}{$\begin{array}{l}\text { Havia o reconhecimento da } \\
\text { organização na realização de cada } \\
\text { tarefa. }\end{array}$} & Concordo & \multirow{2}{*}{$\begin{array}{l}\text { O estagiário se sentia responsável pelos } \\
\text { resultados do trabalho que executava. }\end{array}$} & Concordo \\
\hline & & $61,2 \%$ & & $88,1 \%$ \\
\hline & \multirow{2}{*}{$\begin{array}{l}\text { A organização reconhecia o trabalho } \\
\text { de seus colaboradores mas não o do } \\
\text { estagiário. }\end{array}$} & Concordo & & Concordo \\
\hline & & $58,2 \%$ & & $76,2 \%$ \\
\hline & Considero que o trabalho & Concordo & O estagiário achava que o trabalho que & Concordo \\
\hline & & $65,7 \%$ & & $55,2 \%$ \\
\hline & $\begin{array}{l}\text { Os supervisores colaboravam para a } \\
\text { produtividade (ou aprendizado) dos }\end{array}$ & Concordo & & Concordo \\
\hline Оิ & & $80,6 \%$ & & $88,1 \%$ \\
\hline 원준 & $\begin{array}{l}\text { Na organização as tarefas eram } \\
\text { transmitidas aos estagiários de forma }\end{array}$ & Concordo & & Concordo \\
\hline 这志 & $\begin{array}{c}\text { a contribuir para seu melhor } \\
\text { desempenho. }\end{array}$ & $61,2 \%$ & & $76,2 \%$ \\
\hline & & Concordo & & Concordo \\
\hline & & & & $55,2 \%$ \\
\hline & & Concordo & O estagiário acreditava que podia contar & Concordo \\
\hline ¿ั & & $80,6 \%$ & & $80,6 \%$ \\
\hline 운 월 & A organização incentivava o respeito & Concordo & & Concordo \\
\hline & e a colaboração de todos. & $61,2 \%$ & pelos seus colegas de trabalho. & $86,5 \%$ \\
\hline & & Concordo & O estagiário sentia o espírito de & Concordo \\
\hline & atividades de estágio. & $83,5 \%$ & 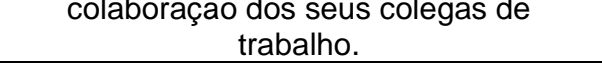 & $73,1 \%$ \\
\hline
\end{tabular}




\begin{tabular}{|c|c|c|c|c|}
\hline & & & \multicolumn{2}{|r|}{ Continuaçãc } \\
\hline & \multicolumn{2}{|l|}{ QVT } & \multicolumn{2}{|l|}{ BEM-ESTAR } \\
\hline & QUESTÕES & TOTAL* & QUESTÕES & TOTAL* \\
\hline \multirow{6}{*}{ 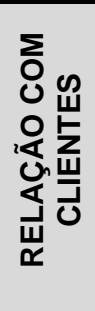 } & \multirow{2}{*}{$\begin{array}{c}\text { A organização tratava os clientes com } \\
\text { respeito. }\end{array}$} & Concordo & \multirow{2}{*}{$\begin{array}{c}\text { Gostava do estilo de relacionamento que } \\
\text { tinha com os clientes. }\end{array}$} & Concordo \\
\hline & & $85 \%$ & & $65,7 \%$ \\
\hline & \multirow{2}{*}{$\begin{array}{c}\text { Na organização existia uma } \\
\text { preocupação em satisfazer os } \\
\text { clientes. }\end{array}$} & Concordo & \multirow{2}{*}{$\begin{array}{c}\text { Eu era tratado com respeito pelos } \\
\text { clientes. }\end{array}$} & Concordo \\
\hline & & $79,1 \%$ & & $74,7 \%$ \\
\hline & \multirow{2}{*}{$\begin{array}{l}\text { A organização incentivava que seus } \\
\text { colaboradores tivessem bons } \\
\text { relacionamentos com os clientes. }\end{array}$} & Concordo & \multirow{2}{*}{$\begin{array}{l}\text { Meu relacionamento com os clientes } \\
\text { influenciavam positivamente o meu } \\
\text { trabalho. }\end{array}$} & Concordo \\
\hline & & $71,7 \%$ & & $61,2 \%$ \\
\hline \multirow{6}{*}{ 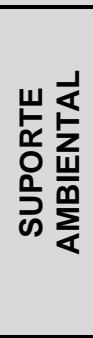 } & \multirow{2}{*}{$\begin{array}{c}\text { A organização fornecia equipes de } \\
\text { segurança para prevenção de perigos } \\
\text { no trabalho. }\end{array}$} & Concordo & \multirow{2}{*}{$\begin{array}{l}\text { O estagiário sentia que o ambiente de } \\
\text { trabalho favorecia a sua saúde. }\end{array}$} & Concordo \\
\hline & & $53,7 \%$ & & $53,7 \%$ \\
\hline & \multirow{2}{*}{$\begin{array}{c}\text { A organização disponibilizava } \\
\text { materiais para execução das tarefas } \\
\text { solicitadas. }\end{array}$} & Concordo & \multirow{2}{*}{$\begin{array}{c}\text { O estagiário tinha a infraestrutura } \\
\text { material necessária para a execução do } \\
\text { seu trabalho. }\end{array}$} & Concordo \\
\hline & & $88 \%$ & & $91 \%$ \\
\hline & \multirow{2}{*}{$\begin{array}{l}\text { A organização era preocupada com a } \\
\text { prevenção de acidentes e perigos de } \\
\text { trabalho. }\end{array}$} & Concordo & \multirow{2}{*}{$\begin{array}{c}\text { O estagiário possuía equipe de } \\
\text { segurança que preveniam os perigos do } \\
\text { trabalho. }\end{array}$} & Concordo \\
\hline & & $61,2 \%$ & & $47,8 \%$ \\
\hline \multirow{6}{*}{$\frac{\text { 을 }}{\frac{1}{4}}$} & \multirow{2}{*}{$\begin{array}{l}\text { A organização proporcionava salário } \\
\text { justo e de acordo com o mercado. }\end{array}$} & Concordo & \multirow{2}{*}{$\begin{array}{c}\text { O estagiário considerava justo o salário } \\
\text { que recebia. }\end{array}$} & Concordo \\
\hline & & $47,8 \%$ & & $50,8 \%$ \\
\hline & \multirow{2}{*}{$\begin{array}{c}\text { A organização pagava o salário de } \\
\text { acordo com a tarefa que o estagiário } \\
\text { executava. }\end{array}$} & Discordo & \multirow{2}{*}{$\begin{array}{l}\text { O estagiário julgava que o seu salário era } \\
\text { compatível com o salário do mercado. }\end{array}$} & Concordo \\
\hline & & $41,8 \%$ & & $49,3 \%$ \\
\hline & \multirow{2}{*}{$\begin{array}{c}\text { A organização se preocupava com o } \\
\text { pagamento. }\end{array}$} & Concordo & \multirow{2}{*}{$\begin{array}{c}\text { O salário condizia com as tarefas que } \\
\text { executava. }\end{array}$} & Concordo \\
\hline & & $76,1 \%$ & & $53,7 \%$ \\
\hline
\end{tabular}

FONTE: Elaborado a partir de Paz (2004), Warr (2007) e Dessen (2010).

*Os números se referem aos dados da pesquisa

Participaram da pesquisa 67 alunos: $41,8 \%$ do curso de Administração; $23,9 \%$ do curso de Ciências Contábeis e $34,3 \%$ do curso de Ciências Econômicas. Quanto ao sexo, $68,7 \%$ são do sexo feminino e $31,3 \%$ do sexo masculino. Quanto ao estado civil, tem-se $73,1 \%$ de respondentes solteiros, $20,9 \%$ casados, $4,5 \%$ outro e $1,5 \%$ divorciado. Quanto a faixa etária dos participantes, $94 \%$ dos respondentes tem entre 20 e 30 anos e $6 \%$ entre 31 a 40 anos.

Quanto ao ano de realização das atividades de estágio, 35,8\% no ano de 2014 , e $64,2 \%$ no ano de 2015, o que se pode notar um grande aumento desta prática de ensino.

A seguir, apresentam-se alguns dados mais pertinentes encontrados na pesquisa.

- AUTONOMIA: Quanto à QVT, 73,2\% dos respondentes consideram que os supervisores davam liberdade para que os colaboradores realizassem suas atividades e tomassem algumas decisões; mais de $77 \%$, não acreditam que organização considerava a opinião de todos os colegas menos a dele e $61 \%$ consideraram que a empresa dava autonomia para apresentar solução para os problemas. Quanto ao bem-estar, pode-se verificar que menos da metade dos respondentes entendem que sua opinião era considerada na organização em que trabalhava, mas quase 30\% afirmaram que 'não concordam nem discordam' da afirmação, demonstrando uma falta de posição. Estes dados refletem que, quanto ao indicador Autonomia, a QVT - atividades de responsabilidades da organização sendo atendidas -, mas, quanto ao bem-estar, os estagiários não percebem como positivo. Conforme Dessen (2010), a autonomia é a percepção do funcionário sobre a liberdade que possui para utilizar seu estilo pessoal na execução do seu trabalho, mostrando, assim, que os estagiários não têm esse sentimento.

- IDENTIFICAÇÃO COM O TRABALHO: Com relação à QVT, verificou-se que $73 \%$ dos respondentes consideram que a organização possibilitava o desenvolvimento do seu potencial, mas houve uma variação grande nas respostas quando questionado sobre a variação das tarefas para que pudesse usar capacidades diferentes - 35\% assinalaram que havia variação das tarefas. No entanto, quase $80 \%$ afirmam que as organizações ofereciam condições para a aprendizagem com a realização do estágio. Já quanto ao bem-estar, verificou-se que $76 \%$ consideram que, quando trabalhavam na organização, desenvolviam os seus potenciais e mais de $61 \%$ sentiam-se bem com o grau de interesse que as tarefas os despertavam. $\mathrm{E}$ ainda $59 \%$ gostavam da variedade de tarefas que realizava. Dessa forma, os dados encontrados, quando confrontados com as definições de identificação com o trabalho, tanto com a QVT quanto com o bem-estar, estão interligados. Este indicador é correlacionado com dimensões da QVT que corroboram com itens como: oportunidade de utilização e desenvolvimento da capacidade. 
- OPORTUNIDADE DE CRESCIMENTO: Existe uma divergência grande entre as respostas, quando questionados se a empresa possuía um programa de carreira e crescimento para seus colaboradores, quase $39 \%$ responderam que não. Quanto à organização proporcionar chances de efetivação dos estagiários, $50,7 \%$ considera que não. E quando questionados se a organização capacitava os colaboradores antes de preferir trazer profissionais de fora, $28,3 \%$ responderam que não. Quanto ao bemestar, $58,2 \%$ dos respondentes sentiam-se bem com a oportunidade que tinham de aprender por meio de capacitações oferecida. Mas, quando questionados se gostavam do sistema de promoção daquela empresa, 29,8\% mencionaram que não, e 40,4\% não se posicionaram. Ao considerar se tinham conhecimento dos critérios utilizados para as promoções dos colaboradores, $31,3 \%$ consideraram que não. A definição do indicador "Oportunidade de crescimento" para Paz (2004) e Warr (2007) significa gostar do sistema de promoção e ter conhecimentos de seus critérios, ter oportunidades de se capacitar e de realizar treinamentos relevantes para o trabalho. Nos resultados apresentados, a maioria dos estagiários não se posicionou quanto ao conhecimento de critérios e dos sistemas de promoções, o que mostra desinteresse sobre $o$ assunto.

- IDENTIFICAÇÃO COM A ORGANIZAÇÃO: Quanto à 'Identificação com a organização', 61,2\% dos respondentes acreditam que o mérito do sucesso da organização era compartilhado com a equipe de colaboradores, mais de $58 \%$ responderam que a organização proporcionava um ambiente no qual os colaboradores sentiam orgulho em fazer parte dela e $64,2 \%$ sentiam que a organização acreditava que todas as tarefas eram essenciais para a sociedade. No bem-estar, mais de $58 \%$ dos respondentes acreditava no resultado do trabalho da organização no qual faziam parte, 55,2\% tinham orgulho de pertencer à sua organização, porém, quando questionados sobre a sua identificação com a organização, a maioria não se posicionou. Van Horn et al. (2004), Warr (2007) e Ferreira Vasconcelos (2013) corroboram com o conceito do indicador "Identificação com a organização" como o sentimento de admiração, orgulho, confiança e identificação pela organização, percebendo-a como séria e acreditando nos resultados do trabalho que é realizado na mesma.

- VALORIZAÇÃO COM O TRABALHO: Ao se analisar o indicador 'Valorização com o trabalho', constatou-se, no quesito QVT, que mais de $61 \%$ dos respondentes reconheceu na organização a realização de cada tarefa que se realizava para a eficácia do processo, mais de $58 \%$ acreditavam que a organização reconhecia o trabalho de seus colaboradores, mas não o do estagiário e $65,7 \%$ consideram que o trabalho desenvolvido pela organização é importante para a sociedade. Quanto ao bem-estar, $88,1 \%$ dos respondentes sentiam-se responsáveis pelos resultados do trabalho que executavam; $76,2 \%$ conheciam os resultados que o seu trabalho trazia para a organização, e 55,2\% achavam que o trabalho que desempenhavam era essencial para a sociedade. Para Paz (2004) e Warr (2007), o indicador "Valorização com o trabalho" significa conhecer os resultados do seu trabalho e considerá-lo importante, tanto para a organização quanto para a sociedade, o que relaciona positivamente com os resultados obtidos na pesquisa.

- RELAÇÃO COM A CHEFIA: Quanto à QVT, constatou-se que $80,6 \%$ dos respondentes consideram que os supervisores colaboravam para a produtividade (ou aprendizado) dos estagiários, $61,2 \%$ dos respondentes acreditam que na organização, as tarefas eram transmitidas aos estagiários de forma a contribuir para o seu desempenho. E, ainda, $83,5 \%$ entendiam que, na organização, os estagiários eram tratados com respeito e consideração. No bem-estar, $88,1 \%$ dos respondentes tinham supervisores que colaboravam para a sua produtividade, $76,2 \%$ acreditavam que seus supervisores transmitiam as informações importantes para o seu desempenho no trabalho e mais de $55 \%$ gostavam da maneira com seu supervisor o tratava. Com relação ao indicador 'Relação com a chefia', Paz (2004), Warr (2007) e Ferreira Vasconcelos (2013) ressaltam que é preciso ter uma chefia que seja atenciosa, aberta, justa, respeitosa e competente, ou seja, corroboram com os resultados da pesquisa, visto que há relação entre o conceito e a prática.

- RELAÇÃO COM OS COLEGAS DE TRABALHO: Na visão da QVT, apurou-se que a organização prezava por tarefas no coletivo, colaborando para a interação entre os colegas de trabalho com $80 \%$ das respostas positivas nesse quesito. Notou-se que $61,2 \%$ acreditavam que a organização incentivava respeito e a colaboração de todos e $83,5 \%$ entendiam que a organização oferecia apoio nas atividades de estágio. $\mathrm{Na}$ visão do bem-estar, $80,6 \%$ dos respondentes acreditava que podiam contar com seus colegas de trabalho para desempenhar suas atividades, mais de $86 \%$ era tratado com respeito pelos seus colegas de trabalho e $73,1 \%$ sentiam-se bem com o espírito de colaboração dos seus colegas de trabalho. Isso constata as considerações de Paz (2004), Van Horn et al. (2004), Warr (1987, 2007) e Ferreira Vasconcelos (2013). Os autores ressaltam que para se ter um bom relacionamento com os colegas de trabalho, é necessário ter um relacionamento com colegas baseado na amizade, confiança, respeito, apoio e colaboração. 
- RELAÇÃO COM CLIENTES: Quanto à QVT, 85\% dos respondentes entendiam que a organização tratava os seus clientes com respeito; $79,1 \%$ acreditavam que na organização existia uma preocupação em satisfazer os clientes, e $71,7 \%$ observaram que a organização incentivava que os seus colaboradores tivessem bons relacionamentos com os clientes. No quesito bem-estar, $65,7 \%$ dos respondentes gostavam do estilo de relacionamento que tinham com seus clientes, $74,7 \%$ eram tratados com respeito pelos clientes e $61,2 \%$ entenderam que o relacionamento com os clientes influenciava positivamente no trabalho deles. Gostar do relacionamento que mantém com os clientes e o perceber como respeitoso e como uma influência positiva para o trabalho são características abordadas por Paz $(2004)$ e Warr $(1987,2007)$ no indicador "relação com clientes" e corrobora com os resultados apresentados.

- SUPORTE AMBIENTAL: No quesito QVT, a organização fornecia equipes de segurança para prevenção de perigos no trabalho com 53,7 das respostas positivas nessa afirmação. Percebeu-se também que $88 \%$ dos respondentes entendiam que a organização disponibilizava materiais para execução das tarefas solicitadas e $61,2 \%$ acham que a organização era preocupada com a prevenção de acidentes e perigos de trabalho. No quesito bem-estar, em todas as afirmações houve respostas positivas: $53,7 \%$ sentiam que 0 ambiente de trabalho favorecia a sua saúde, $91 \%$ tinham a infraestrutura material necessária para a execução do seu trabalho. Já, quando questionados sobre se possuíam equipe de segurança que preveniam os perigos do trabalho, $47,8 \%$ responderam que sim; $23,9 \%$ não souberam opinar e $28,3 \%$ responderam que não. Corroborando com estes resultados, Paz $(2004)$ e Warr $(1987,2007)$ entendem que, para se ter um suporte ambiental, é necessária infraestrutura material e equipamentos de segurança, além de trabalhar em um ambiente que contribua para a saúde do trabalhador.

- SALÁRIOS: Na visão de QVT, 47,8\% dos respondentes acreditam que a organização proporcionava salário justo, de acordo com o mercado; $28,4 \%$ não se posicionaram, e $23,9 \%$ se posicionaram contra a afirmação. Quando questionados sobre a preocupação da organização relativa ao salário de acordo com a tarefa que executavam, 41,8\% discordam dessa afirmação; $20,9 \%$ não se posicionaram, e $37,3 \%$ concordam. $76,1 \%$ dos respondentes acreditavam que a organização se preocupava com o pagamento deles. Na variável bem-estar, pôde-se certificar que $50,8 \%$ dos respondentes consideravam justo o salário que recebiam; 49,3\% julgavam que o salário deles era compatível com o salário do mercado; $20,9 \%$ não se posicionaram, e $29,8 \%$ discordam da afirmação. E, ainda, $53,7 \%$ dos respondentes acreditam que o seu salário condizia com as tarefas que eles executavam. Para que possa ocorrer resultado satisfatório nesse indicador, Paz (2004) e Warr $(1987,2007)$ propõem que se deva gostar do salário, considerando-o justo e suficiente para satisfazer as expectativas. Na pesquisa, constatou-se que há relação direta entre o conceito dos autores e das afirmações propostas para se obter resultados satisfatórios.

\section{CONSIDERAÇÕES FINAIS}

Esta pesquisa foi realizada com o objetivo de analisar o entendimento dos alunos que tiveram experiência com a atividade de estágio as atividades de estágio, para identificar a contribuição na formação pessoal, na QVT e no bem-estar dos estagiários.

Com relação aos dados obtidos, pode-se destacar que os estagiários estão satisfeitos com a autonomia que possuem na organização e são ouvidos, porém quanto ao bem-estar, sentem-se com pouca liberdade. Além disso, é possível evidenciar que a organização não se preocupava com a variedade das tarefas que os funcionários executavam. Porém, os estagiários consideravam que seu potencial era desenvolvido, sentiam-se bem com o grau de interesse das tarefas e gostam da variedade de tarefas que eles executavam.

Também se pode destacar a falta de interesse das organizações, no que diz respeito ao programa de carreira, também que não proporcionavam chances de efetivação. Entretanto, os estagiários se sentem bem com relação às capacitações oferecidas pela organização e quanto ao sistema de promoção, embora não conheçam os critérios para tal. Outro resultado relevante para a pesquisa é que, tanto à QVT quanto ao bem-estar ocupacional, os resultados foram positivos com relação à "Identificação da organização". Como exemplo, demonstrou-se que o mérito do sucesso da organização era sempre compartilhado com a equipe e ela acreditava que todas as tarefas eram essenciais para a sociedade, os estagiários tinham orgulho de pertencer à organização e se identificavam com ela. Cabe ressaltar, ainda, que as organizações reconheciam o trabalho de seus colaboradores, mas não o do estagiário, porém os respondentes se sentiam responsáveis pelas suas tarefas e reconheciam os resultados que seu trabalho trazia, acreditando que era essencial para a sociedade.

Dados positivos quanto à QVT, no que tange ao bem-estar ocupacional, foram constatados em indicadores como "relação com a chefia", "relação com os colegas", "relação com os clientes" e "suporte ambiental". Quanto ao salário, o único item que não corresponde positivamente é a respeito da QVT quanto 
a relação entre tarefas e os salários.

De maneira geral, os resultados quanto ao bem-estar são mais satisfatórios do que com relação aos dados de QVT. Ou seja, os estagiários sentem-se bem na organização na grande maioria das questões, porém quando perguntados sobre o papel da organização, as respostas são mais vagas ou menos satisfatórias do que quanto ao bem-estar. A atividade de estágio contribuiu para a sociedade formando o seu estagiário para o mercado de trabalho, pois como foi constatado, os estagiários entendem o processo do seu trabalho e acreditam que suas atividades são fundamentais para a sociedade. Os estagiários vislumbram o estágio como uma oportunidade de aprendizado que o ajudará na sua atuação futura como profissional, tornando-o um profissional mais seguro.

De maneira a colaborar com estudos futuros, pode-se sugerir que a pesquisa seja aplicada com estagiários de outras áreas e também com os gestores das organizações que possuem estagiários em seu quadro de colaboradores, podendo, assim, entender melhor a visão da organização quanto a proporcionar ambientes favoráveis ou não ao crescimento dos estagiários.

\section{REFERÊNCIAS}

BRASIL. Lei no 11.788, de 25 de setembro de 2008. Dispõe sobre o estágio de estudantes. Diário Oficial, Brasília, DF, 25 set. 2008. Disponível em: http://bem-estar.planalto.gov.br/ccivil_03/_ato2007-2010/2008/lei//11788.htm. Acesso em: 24 mai. 2016.

CODO, Wanderley. Por uma psicologia no trabalho: ensaios. 1. ed. São Paulo: Casa do Psicólogo, 2006.

COLOMBO, I.M.; BALLÃO, C. M. Histórico e aplicação da legislação de estágio no Brasil, Educar em Revista, Curitiba, n. 53, jul./set., 2014,

DESSEN, Marina Campos. Indicadores de bem-estar pessoal nas organizações: o impacto da percepção da cultura, do perfil pessoal e de ações de qualidade de vida no trabalho e de qualidade de vida do trabalhador. 2010. vii, 233 f., il. Tese (Doutorado em Psicologia Social, do Trabalho e das Organizações). Universidade de Brasília, Brasília, 2010.

DESSEN, M.; PAZ, M. G. T. Validação do instrumento de indicadores de bem -estar pessoal nas organizações , Psicologia em Estudo (Maringá), 15(2), p. 409-418, 2010.

ESPINOSA, Malva; MORRIS, Pablo. Calidad de vida en el trabajo: percepciones de los trabajadores. Gobierno de Chile, Dirección del Trabajo, Departamento de Estudios, 2002.

FERNANDES, E. C.; GUTIERREZ, L. H. QVT: uma experiência brasileira. Revista de Administração, São Paulo, v.23, n.4, 1988.

FERREIRA VASCONCELOS, Anselmo. Felicidade no ambiente de trabalho: exame e proposição de algumas variáveis críticas. Revista Eletrônica de Administração, [S.I.], v. 10, n. 1, set. 2013.

GIL, Antonio Carlos. Como elaborar projetos de pesquisa. 4. ed. São Paulo: Atlas, 2008.

MORETTI, Silvinha. Qualidade de Vida no Trabalho x auto realização humana. Pós Graduação Recursos Humanos. Blumenau: Instituto Catarinense, 2012.

PAZ, M.G.T. Poder e saúde organizacional: cultura e saúde nas organizações. Porto Alegre: Artmed, 2004.

RAMPAZZO, L. Metodologia científica: para alunos dos cursos de graduação e pós-graduação. 3.ed. São Paulo: Loyola, 2005.

ROESCH, Sylvia Maria Azevedo. Projetos de estágio do curso de administraç ão: guia para pesquisas, projetos e trabalho de conclusão de curso. 1 ed. São Paulo: Atlas, 1996.

SIQUEIRA, Mirlene Maria Matias; PADOVAM, Valquiria Aparecida Rossi. Bases teóricas de bem-estar subjetivo, bemestar psicológico e bem-estar no trabalho. Psicologia: teoria e pesquisa, v. 24, n. 2, p. 201-209, 2008.

SOUZA, G.S.; SANTOS, A.R.; DIAS, V.B.; Metodologia da pesquisa científica: a construção do conhecimento e do processo de aprendizado. Porto Alegre: Animal, 2013.

VAN HORN, Joan E.; TARIS, Toon W.; SCHAUFELI, Wilmar B.; SCHREURS, Paul J. G. The structure of occupational wellbeing: a study among Dutch teachers. Journal of Occupational and Organizational Psychology, v. 77, n. 3, p. 365-375, September, 2004

WARR, P.B. Work, unemployment and mental health. Oxford: Oxford Science Publication, 1987.

WARR, P.B. Work, happiness and unhappiness. New Jersey: Lawrence Erlbaum Associates, 2007.

ZABALZA, M.A. $O$ estágio e as práticas em contextos profissionais na formação universitária. São Paulo: Cortez, 2015.

ZANELLI, J. C.; BORGES-ANDRADE, J. E.; BASTOS, A. V. B. (Org.). Psicologia, organizações e trabalho no Brasil. 2. ed. Porto Alegre: Artmed, 2014. 616 p. 